Encuentro No. 101, 82-85, 2015

\title{
Comentario sobre el libro de Rosa Salaverry, Una vida es una historia para contar
}

\section{Mario Urtecho*}

Acompañar a doña Rosa Salaverry (doña Cuta) en la edición, publicación y presentación de Una vida es una historia para contar ha sido una experiencia especial, porque además fue una ocasión inapreciable para compartir la franca y fresca amistad de ella y de su esposo, el Dr. Ernesto Castillo, don Tito.

Estas memorias cautivantes, reunidas en diez secciones que abarcan 360 páginas, las escribió doña Cuta a mano, como los antiguos amanuenses, con su hermosa caligrafía de finos arabescos trazada con grafito o con bolígrafo. Y fue a mano, no a máquina, porque así es como ella siente -me dijo- "que lo que escribo me lo saco del corazón”. Fueron incontables las horas dedicadas a re-crear eventos centrales de su existencia, reconstruidos con paciencia de orfebre y meticulosidad

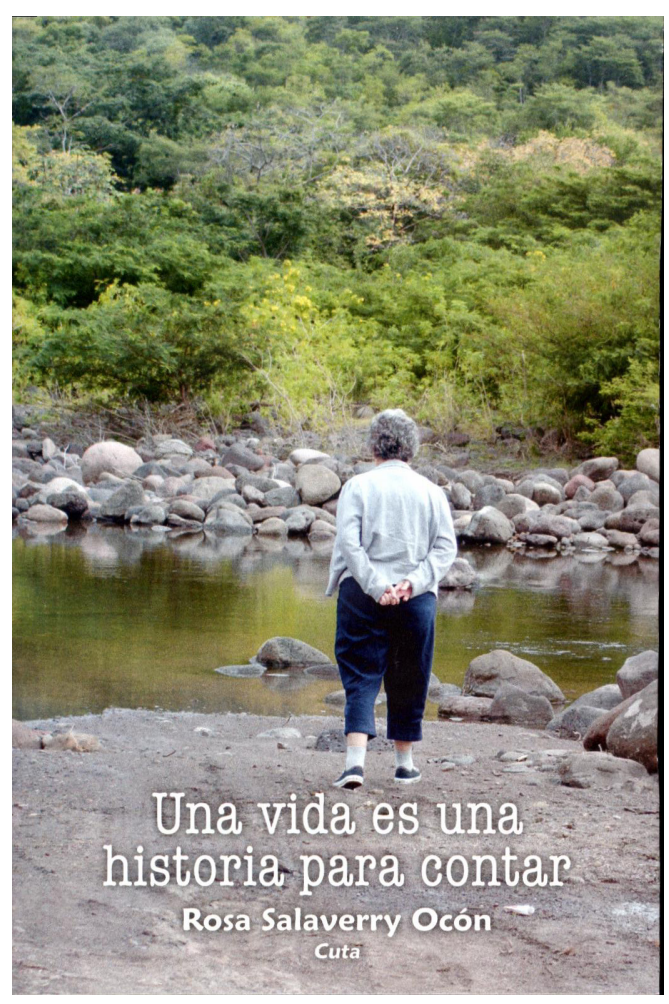
de alfarera, para que sus palabras dieran testimonio de la singular senda que ha recorrido hasta hoy. 
Sin pretensiones literarias doña Cuta contó su vida, como contaban las suyas nuestros abuelos, casi siempre ligadas a la historia de Nicaragua. Sin embargo, a pesar de tratarse de sus vivencias, logró algo en extremo difícil, como es ser a la vez sujeto de sus recuerdos y contarlos sin destacar su rol de protagonista principal. Y lo hizo tan bien que a la par de la suya contó además hechos de las historias de otras personas.

Leer las memorias de doña Cuta es abrir una ventana y asomarse a la Granada de inicios del siglo XX, a la constancia genealógica que la antecedió, a las casonas señoriales y las calles empedradas, a los rasgos que definían a la sociedad de entonces, a paisajes, personajes y familias avecindadas en El Palenque y El Consulado, a la vida de aquella niña de colochos rubios que lloraba mientras aprendía las primeras letras y las fastidiosas tablas de sumar.

Aquí perduran entrañables amistades, con sus juegos, algarabías y osadías, como la de aquellas muchachas a quien alguien les aseguró que san Antonio era el indicado para conseguirles novio, y con más ilusión que devoción raptaron su efigie de la casa de las niñas Bermúdez, tan devotas ellas, que en el sosiego de sus aposentos dormía el Cristo del Santo Entierro. Hubo regaños, rezos de desagravio y risas en el vecindario.

Aquí vemos su primera comunión, las estrecheces económicas de la familia, las vacaciones a fincas vecinas de Malacatoya o donde el tío David, en Acoyapa; y hasta sentimos la fresca brisa del ahora amenazado Cocibolca, surcado por Cuta y Lucía a bordo del emblemático Vapor Victoria, rumbo a Ometepe con el abuelo Justiniano. Pero también están los días infaustos que impactaron sus infancias y ayudaron a forjar el temple que aquellas niñas necesitarían para enfrentar los retos que les había deparado la vida.

Y como versificó Darío, “quién que Es, no es romántico?”. Y el amor con Ernesto Castillo, el único de su vida, fue tan intenso que la tarde del 21 de abril de 1956, el juez local, Adolfo Arana, los casó por lo civil en la casa de doña Emelina - mamá de Irma y del Duende Prego, amigo entrañable de los dos-, y para que Granada entera lo supiera, con repiques de campanas monseñor Vílchez unió a aquellos muchachos insurrectos en la iglesia de Xalteva. De eso hace ahora 59 años, 1 mes, 1 semana, 8 hijos, 25 nietos y 9 bisnietos. Desde entonces ellos dos han sido indivisibles, sin perder su individualidad.

Pero lejos están sus memorias de ser un anecdotario. Doña Cuta ha desandado su vida con respeto, armonía, coherencia y valores que, como les ocurre a algunas especies, están en vías de extinción, valores como la verdad, la transparencia y la honestidad consigo y los demás, según la regla que dicta su diario vivir: decir lo que piensa y hacer lo que dice.

Y asumieron la vida con madurez y valentía. Un mediodía, radicados en Managua, llegó el poeta Beltrán Morales acompañado de un joven y pidieron hablar con el Dr. Castillo. El muchacho había sido su alumno en la UCA, acababa de asaltar un banco, la Guardia lo buscaba para matarlo y venían a pedirle que lo ocultara en su casa. Así conoció doña Cuta el rostro del Frente Sandinista, y aunque conversó varias veces con él, sólo conoció su identidad cuando aquel muchacho cayó combatiendo contra guardias, tanquetas y aviones allá por Las Delicias del Volga. El hogar de doña Cuta y don Tito fue refugio y lugar de reuniones de clandestinos, 
Encuentro №. 101, 82-85, 2015

y fue tanta la compartimentación aprendida, que Carlos Fonseca y Carlos Agüero estuvieron varios días bajo ese mismo techo sin enterarse el uno de la presencia del otro.

Varias veces, como en la leyenda de Sísifo, reiniciaron camino en el aspecto económico. Una de ellas a causa del terremoto, que acabó con aquella célebre librería, Club de Lectores, donde ellos dos y el joven poeta Luis Rocha Urtecho vendían libros legales y prohibidos, y que servía de fachada para que la gente perseguida por la tiranía, como Ricardo Morales Avilés, dejaran mensajes o entablaran contacto con gente que andaba "legal". Por esas ironías que evidencian la ignorancia del poder, una de tantas veces que los sicarios de la OSN les decomisaron libros, se llevaron el lote completo de La revolución dietética, pero dejaron intacta La sagrada familia, de Marx y Engels, pensando que se trataba de la familia de José, María y el niño Jesús.

La persecución de la dictadura obligó a la familia Castillo Salaverry a exiliarse. De la noche a la mañana y de manera furtiva se instalaron en Costa Rica, en una casa hacienda alquilada en las afueras de San José, que muy pronto se convirtió en base de operaciones del Frente Sandinista. Por allí pasó un gentío que doña Cuta recuerda con nostalgia, respeto y aprecio: Daisy Zamora, Tita Valle, Rosario Murillo, Chepe León Talavera, Nicho Marenco y varios más, que allí instalaron los equipos de Radio Sandino y a diario informaban sobre los avances de la guerra y arengaban al pueblo nicaragüense a sumarse a la insurrección final.

En sus recuerdos y aprecios también están Idania Fernández, Dora María Téllez, Mónica Baltodano, Tulita Guerrero, Juanita Bermúdez y otras mujeres de ñeque. Con trazos sencillos y precisos esbozó perfiles de la personalidad de Herty Lewites, Gaspar García Laviana, Humberto Ortega, Ernesto Cardenal, Víctor Tirado, Henry Ruiz -de quien se declara fan-, Daniel Ortega, Miguel D'Escoto, Fernando Cardenal, Carlos Tünnermann, Joaquín Cuadra, Sergio Ramírez, Emilio Baltodano, Tito Castillo, Arturo Cruz y demás integrantes del Grupo de Los Doce, y de otras personas que incluso vivieron en su hogar.

En septiembre de 1978, los colmillos de la tiranía desgarraron el alma de la familia. Ernesto Castillo Salaverry, quien había dejado sus estudios en Barcelona para sumarse a la guerrilla, cayó combatiendo en León. El joven Ernesto, como Leonel Rugama, era poeta, y tenía la misma edad de Rugama cuando se integró a la inmensa pléyade de muchachas y muchachos que trocaron ilusiones por fusiles y decidieron vivir como los santos, y que son desde entonces nuestros santos laicos, como Luisa Amanda, Angelita, Arlen, Mildred, Araceli, Panchito Gutiérrez, Ricardo y Armando Talavera Salinas, y tantas almas nobles inmoladas en el vértigo de la guerra para que en Nicaragua jamás hubiese otra dictadura.

Hay mucho más que leer en Una vida es una historia para contar, que nos hará recordar historias que están en nuestra memoria, en nuestro inconsciente colectivo, frescas, quizá desvaídas, o peor aún, casi olvidadas. Las memorias de doña Rosa Salaverry Ocón, doña Cuta, incentivan a detener un poco la marcha del vivir para escribir sobre nuestra historia reciente, la que muchos de ustedes protagonizaron en el norte, el centro, el sur, oriente y occidente, en el Pacífico y el Caribe nicaragüense, $\mathrm{y}$ allende las fronteras.

Es nuestro deber rescatar tantas ilíadas y tantas odiseas, para que la historia y la memoria de nuestra Nicaragüita no queden aniquiladas por el olvido, pero, sobre 
todo, para que a nuestros nietos, bisnietos y tataranietos nadie les cuente cuentos chinos.

Acudo poco a referencias literarias, pero a propósito de resistir, comparto estas palabras de El libro de la risa y el olvido, del checo Milan Kundera:

Para liquidar a las naciones lo primero que se hace es quitarles la memoria. Se destruyen sus libros, su cultura, su historia. Y luego, viene alguien y les escribe otros libros, les da otra cultura y les inventa otra historia. Entonces, la nación comienza lentamente a olvidar lo que es y lo que ha sido. Y el mundo circundante lo olvida aún mucho antes.

¡Gracias!

Ahuacalí, Managua, 25 de mayo 2015 